HEAO

\section{Picking Up the Pieces}

by our Washington Correspondent DURING the past few weeks NASA officials have been quietly picking up some of the pieces of the High Energy Astronomy Observatory (HEAO) programme, which in January became a casualty of the Administration's drive to hold down federal expenditure. They have put together a plan to launch three small HEAO satellites with AtlasCentaur rockets between 1977 and 1979, and to complete the programme with heavier satellites launched by the shuttle in the early 1980s. The emphasis in the first part of the revamped programme will be on X-ray studies.

The plan developed partly from a meeting, held shortly after the Office of Management and Budget killed the programme, of those who would have flown experiments on the original HEAO satellites. It has since been endorsed by the Space Science Board of the National Academy of Sciences. Although still rather tentative, the chief elements of the plan probably will not change much, but Dr John Naugle, Associate NASA Administrator for Space Science, said last week that the HEAO programme will remain suspended "for at least a year" while the details are settled.

As it now stands, the plan is for the first scaled-down HEAO satellite to do an X-ray survey, and for the second to study individual point sources of $\mathrm{X}$-rays. The third satellite will carry gamma ray and cosmic ray detectors for a survey, and the shuttle-launched missions will carry the heavier gamma ray and cosmic ray experiments.

As originally planned, the HEAO programme would have consisted of two large satellites launched by Titan rockets in 1975 and 1977, followed by two more large satellites launched by the shuttle in the early 1980s. Each satellite would have carried a range of experiments to detect $\mathrm{X}$-rays, gamma rays and cosmic rays, and each would have carried a scientific payload of about 12,000 pounds. In contrast, the Atlas-Centaur is capable of launching high energy astronomy satellites with a scientific payload of 2,800 pounds.

Why concentrate on X-ray studies for the scaled-down HEAO missions? Apart from the fact that most of the gamma ray and cosmic ray studies originally planned for the programme are too heavy to be launched by the Atlas-Centaur, it is felt that the results from the first Small Astronomy Satellite, Uhuru, which was launched in 1971 , provide a good base on which to build. Moreover, the follow-up to Uhuru, SAS-C, which is now scheduled for launch in 1975, should provide even more exciting results as a curtain-raiser to the scaled-down HEAO mission. As Dr Robert Halpern, Programme Manager of HEAO, said last week, "We know we have something to grab hold of, the other two fields have promise, but it's just that-promise".

$\mathrm{X}$-ray astronomers are, understandably, relatively pleased by the plan to concentrate initially on their subject. Dr Herbert Friedman, of the Naval Research Laboratory, for example, said last week that although the revised programme is a "serious fallback" from the original plans, he strongly supports the plan to concentrate on X-ray studies. He pointed out that the HEAO experiment will be much more sensitive than Uhuru, perhaps even picking up several thousand sources compared with about 125 detected by Uhuru. The Xray detectors on the reconstructed HEAO mission, which will be about 2 square metres, should also be capable of determining individual pulse

\section{ENERGY \\ Another Apollo}

by our Washington Correspondent

AN energy research and development programme, akin to the Apollo or Manhattan projects, has been proposed by Senator Henry M. Jackson, the Washington Democrat who has effectively staked out the chief claim to energy matters on Capitol Hill. Backed by Senator Jennings Randolf, Chairman of the Senate Public Works Committee, Senator Warren Magnuson, Chairman of the Senate Commerce Committee, and some 25 other senators, Jackson has introduced a bill calling for expenditures of $\$ 20,000$ million by the federal government on energy research and development over the next ten years. The objective, Jackson said last week, is to make the United States self-sufficient in energy supplies by 1983 .

Suggesting that present federal funds for energy research and development programmes are inadequate and illogically distributed, Jackson has proposed that they should be increased to $\$ 1,607$ million in the 1974 fiscal year, and that they should reach nearly $\$ 2,000$ million in 1977 . This compares with $\$ 772$ million which the Administration has requested for next year, and which President Nixon proudly proclaimed in his recent message on natural resources.

Jackson's bill also proposes the setting up of an Energy Research Management Project, composed of officials from federal agencies involved with energy matters, to coordinate activities and to fund projects.

The share of the research and development effort devoted to non- shapes from the Crab X-ray pulsar, and perhaps even of picking up the flashes of radiation that some theoreticians have predicted will be discovered coming from the area of black holes.

The new plan has not, of course, pleased everybody. Gamma and cosmic ray scientists are disturbed that if there are cost overruns on the first two missions, the third may be scrapped or at least delayed until the shuttle is available. Their fears may be justified. A year ago, Dr Naugle told the House Committee on Science and Astronautics that the costs of the first two original HEAO missions were then reckoned to be about $\$ 180$ million, and that even if possible development problems were taken into account, the total cost should be less than $\$ 250$ million. Last week, however, a NASA press release said that the cost of the original programme would have been about $\$ 275$ million. nuclear energy would also be substantially increased by Jackson's bill. It calls for the setting up of five corporations, jointly managed by the federal government and by industry, whose business would be to bring new technologies to the point of commercial application. Specifically, the corporations would be involved with coal gasification, shale oil development, advanced power cycles, geothermal resources and coal liquefaction, and the federal share of the effort would range from 50 per cent in the case of shale oil, to 80 per cent for the development of geothermal energy.

What chance does the bill stand of being passed by Congress? For one thing, it has strong bipartisan support, including the chairmen of the three committees most involved, and for another, as Jackson said last week, it will be considered later this year, when petrol rationing may become a reality in some parts of the United States. "I don't think we will have much trouble getting it passed," he said.

Whether President Nixon will agree to it is, however, another matter. $\mathrm{He}$ is now expected to produce his own energy message in late April, but his proposals will certainly be much less extravagant than Jackson's. Congress may have the votes to override a possible Presidential veto, but the Administration would probably not spend all the money even if the bill were rammed through. If the bill is passed in its present form, however, President Nixon would be forced by law to put into effect the institutional arrangements it entails, regardless of whatever he proposes in his own energy message. Jackson has thus neatly scooped the White House. 